\title{
Citologia de impressão na ceratoconjuntivite primaveril
}

\author{
Impression cytology in vernal conjunctivitis
}

\author{
Gustavo Bueno de Camarg'o ${ }^{1}$ \\ Maria Cristina Nishiwaki-Dantas ${ }^{2}$ \\ Jeison de Nadai Barros ${ }^{3}$ \\ Jonathan Clive Lake ${ }^{4}$
}

Trabalho realizado no Departamento de Oftalmologia da Santa Casa de São Paulo.

${ }^{1}$ Residente de Oftalmologia do terceiro ano da Santa Casa de São Paulo.

${ }^{2}$ Chefe do Ambulatório de Córnea e Doenças Externas da Santa Casa de São Paulo.

${ }^{3}$ Tecnólogo em Oftalmologia da Universidade Federal de São Paulo - UNIFESP.

${ }^{4}$ Professor Assistente do Ambulatório de Córnea e Doenças Externas da Santa Casa de São Paulo.

Endereço para correspondência: Gustavo Bueno de Camargo - Rua Álvaro Muller, 1004 - Campinas (SP) CEP 13023-181 - E-mail: guscamargo@ig.com.br

Recebido para publicação em 19.12.2003

Versão revisada recebida em 19.07.2004

Aprovação em 23.07.2004

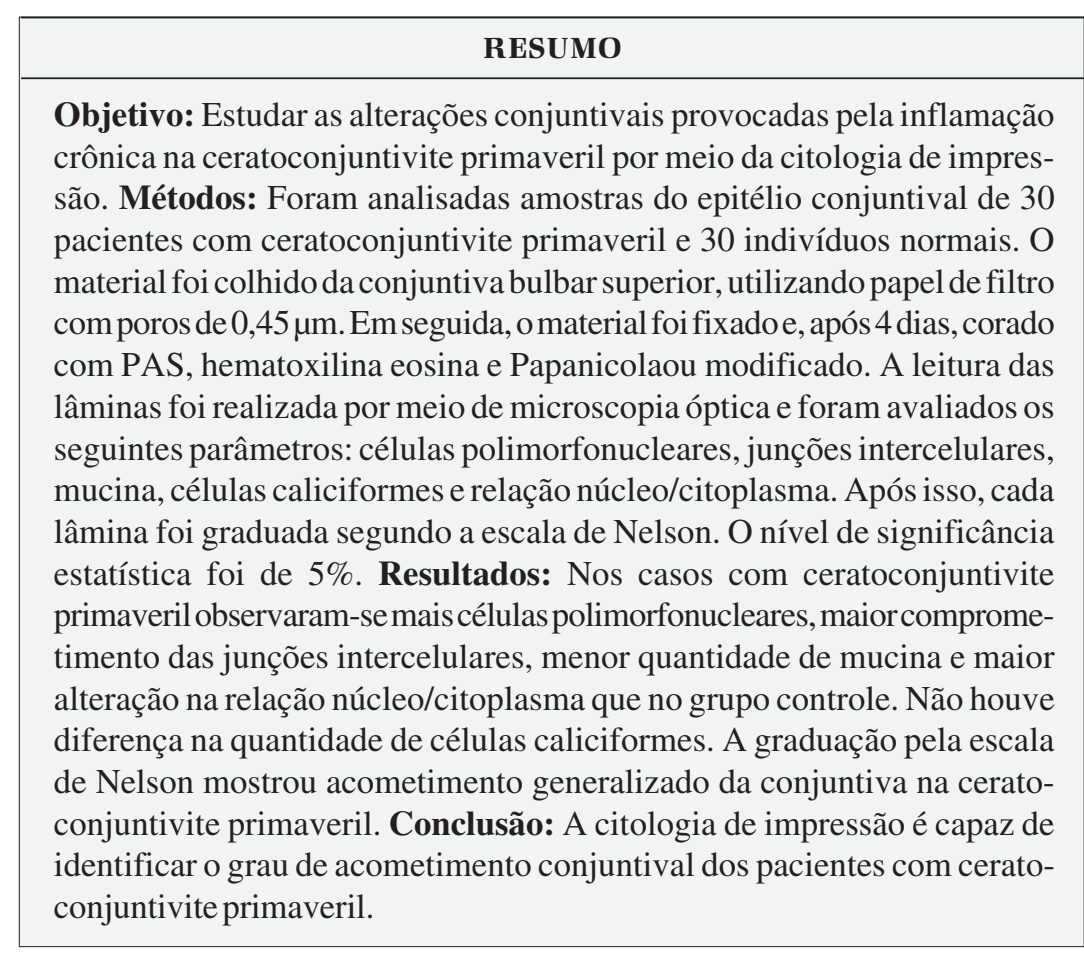

Descritores: Conjuntiva/citologia; Conjuntivite alérgica; Técnicas citológicas

\section{INTRODUÇÃO}

As conjuntivites alérgicas são caracterizadas por processos inflamatórios que acometem a superfície ocular e apresentam intensidade e duração variáveis ${ }^{(1-4)}$. Trata-se de afecção ocular freqüente nos serviços de oftalmologia. Alguns relatos mostram incidência de $20 \%$ da população com algum sinal ou sintoma de alergia ocular ${ }^{(3)}$.

A patogenia da conjuntivite alérgica envolve reação de hipersensibilidade de tipo I, na qual há produção de anticorpos da classe IgE ligados a mastócitos, após contato dos olhos com o alérgeno. Estas células tornamse sensibilizadas e passam a liberar mediadores inflamatórios pré-formados, como a histamina (mediador principal), prostaglandinas e leucotrienos ${ }^{(2)}$. Além disso, a reação de hipersensibilidade do tipo IV, associada às doenças mediadas pelos linfócitos T, pode fazer parte da patogenia da doença ${ }^{(2)}$.

As conjuntivites alérgicas podem ser classificadas em: conjuntivite alérgica sazonal, perene, atópica, papilar gigante e ceratoconjuntivite primaveril $(\mathrm{CCP})^{(2-3)}$. A CCP é a mais freqüente entre as alergias oculares no Ambulatório de Alergia Ocular do Departamento de Oftalmologia da Santa Casa de São Paulo.

A CCP apresenta comportamento sazonal, com piora dos sinais e sinto- 
mas na primavera e no verão e prevalência maior nos países de clima tropical $^{(1,3)}$. As crianças entre 2 e 10 anos de idade são mais atingidas e é mais freqüente no sexo masculino ${ }^{(1)}$. Os principais sintomas são: prurido ocular, sensação de corpo estranho, fotofobia, hiperemia conjuntival, lacrimejamento e presença de secreção mucosa. Há três formas de apresentação da CCP: palpebral, límbica e mista ${ }^{(1)}$. Na forma palpebral, a hipertrofia papilar da conjuntiva palpebral é a característica mais marcante, geralmente com papilas maiores que 1 milímetro na conjuntiva palpebral superior ou papilas gigantes, formadas a partir da coalescência destas. $\mathrm{Na}$ forma límbica, o limbo apresenta aspecto espessado e gelatinoso e pode haver os pontos de Horner-Trantas e as pseudofossetas ${ }^{(5)}$. A forma mista apresenta acometimento da conjuntiva palpebral e limbo. Todas as formas têm acometimento ocular bilateral. $\mathrm{Na}$ $\mathrm{CCP}$ com envolvimento corneal, há presença inicial de ceratite punctata difusa, que pode evoluir para defeito epitelial persistente, conhecido como úlcera em escudo ${ }^{(1)}$.

O diagnóstico na CCP é realizado por meio da história clínica do paciente, dos seus antecedentes pessoais e familiares e do exame biomicroscópico ${ }^{(1-3,6)}$. Exames laboratoriais, como os raspados e biópsias de conjuntiva, são coadjuvantes para o diagnóstico e acompanhamento dos pacientes ${ }^{(3,7)}$.

A citologia de impressão, usada pela primeira vez por Egbert et al em $1977^{(8)}$, é método não invasivo para a avaliação da superfície ocular de pacientes com doenças inflamatórias crônicas e representa uma alternativa para os raspados e biópsias de conjuntiva ${ }^{(1,4,7,9-10)}$. Alguns estudos mostram que a coleta da amostra de células da conjuntiva é rápida e pode ser bem tolerada pelos pacientes ${ }^{(1,9)}$. Além disso, relatos afirmam que a qualidade do material obtido com a citologia de impressão é melhor do que os raspados conjuntivais ${ }^{(1)}$. Na citologia de impressão são avaliados parâmetros citológicos da superfície ocular: distribuição das células caliciformes, presença de células inflamatórias, cromatina nuclear e relações entre o tamanho do núcleo e do citoplasma das células epiteliais da conjuntiva, junções intercelulares e queratinização ${ }^{(1,9)}$. Os dados podem ser reunidos e graduados usando a escala de Nelson ${ }^{(11)}$.

A agressão inflamatória contínua e de longa duração, presente na CCP, pode alterar as funções das células epiteliais da conjuntiva e afetar seu equilíbrio com o filme lacrimal. O objetivo deste trabalho foi avaliar o impacto do processo inflamatório crônico da CCP sobre a superfície ocular por meio da citologia de impressão conjuntival em pacientes do Ambulatório de Alergia Ocular do Departamento de Oftalmologia da Santa Casa de São Paulo.

\section{MÉTODOS}

Foram avaliadas amostras do epitélio conjuntival, por meio de citologia de impressão, de 30 pacientes com diagnóstico de ceratoconjuntivite primaveril, acompanhados no Ambulatório de Alergia Ocular do Departamento de Oftalmologia da Santa Casa de São Paulo, no período de julho a setembro de 2002. Todos os pacientes estavam em tratamento com medicação tópica e não se encontravam em crise. O grupo controle foi formado por 30 pacientes do Laboratório de Doenças Externas Oculares da Escola Paulista de Medicina-UNIFESP, sem acometimento ocular e sem qualquer medicação (tópica ou sistêmica).

O material foi colhido da conjuntiva bulbar superior do olho direito dos pacientes, após instilação de colírio anestésico. Para a coleta, foi utilizado papel de filtro da Milipore Corporation, código de catálogo HAWP304F0, com poros de diâmetro de $0,45 \mu \mathrm{m}$. O papel de filtro foi recortado em fragmentos de acordo com o esquema da figura 1. Após isso, os fragmentos foram esterilizados em óxido de etileno. O papel de filtro foi posicionado sobre a conjuntiva e pressionado por haste de algodão durante 5 segundos, de forma constante. Após isso, o papel foi retirado utilizando pinça sem dente. A aderência da conjuntiva sobre o papel de filtro no momento da retirada (peeling) indicava coleta adequada. O material foi fixado utilizando solução de álcool etílico a 70\%, ácido acético glacial e formaldeído a 37\%, na proporção de 20:1:1, dentro de tubo de ensaio, imediatamente após a coleta, onde permanecia durante 4 dias. Para a coloração da amostra, a técnica empregada foi uma associação de três corantes: ácido periódico de Schiff (PAS), hematoxilina eosina e Papanicolaou modificado ${ }^{(9)}$.

A leitura das lâminas foi realizada por meio de microscopia óptica e sempre pelo mesmo observador do Laboratório de Doenças Externas Oculares da Escola Paulista de Medicina. Os parâmetros avaliados foram: presença de células polimorfonucleares (PMN), junções intercelulares, presença de mucina, quantidade de células caliciformes e relação núcleo/citoplasma. As amostras foram classificadas de 0 a 3, conforme escala de Nelson ${ }^{(11)}$ :

Grau 0: As células epiteliais são pequenas e redondas com citoplasma eosinofílico. O núcleo é grande e basófilo, com relação núcleo/citoplasma de 1:1 ou 1:2. Há muitas células caliciformes ovais com citoplasma intensamente PAS positivo.

Grau 1: As células epiteliais são um pouco maiores, mais poligonais e com citoplasma eosinófilo. O núcleo é menor, com relação núcleo/citoplasma de 1:3. As células caliciformes estão em menor número, mas mantém sua forma oval e o citoplasma intensamente PAS positivo.

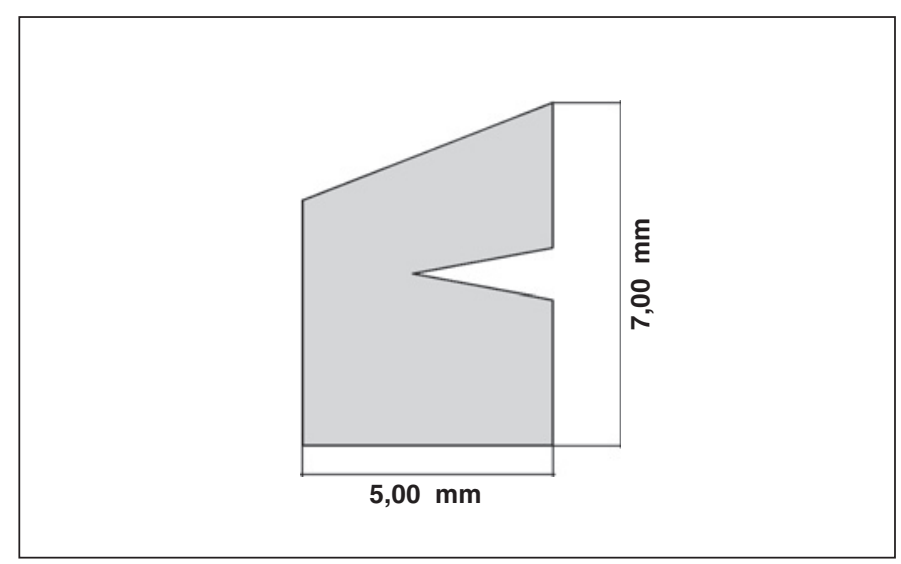

Figura 1 - Forma e dimensões do papel de filtro 
Grau 2: As células epiteliais são grandes e poligonais. Ocasionalmente são multinucleadas e o citoplasma de coloração variável. O núcleo é menor com relação núcleo/citoplasma de 1:4 ou 1:5. As células caliciformes estão marcadamente diminuídas; são menores, com citoplasma pouco PAS positivo e seus limites celulares pouco definidos.

Grau 3: As células epiteliais são grandes, poligonais e com citoplasma basófilo. O núcleo é pequeno, picnótico ou ausente em algumas células. A relação núcleo/citoplasma é maior que 1: 6 . Células caliciformes estão ausentes.

Os resultados obtidos foram analisados usando o teste do Qui-quadrado de tendência linear, pois são dois grupos com variáveis categóricas que guardam relação linear. O nível de significância estatística adotado foi de $5 \%$.

\section{RESULTADOS}

A idade média dos pacientes do grupo com ceratoconjuntivite primaveril foi $12,86 \pm 4,34$ anos ( 6 a 23 anos) e a do grupo controle 20,57 $\pm 3,02$ anos (15 a 28 anos). O grupo com ceratoconjuntivite primaveril foi formado por $18(60 \%)$ pacientes do sexo masculino e $12(40 \%)$ do sexo feminino. O grupo controle foi formado por $12(40 \%)$ pacientes do sexo masculino e 18 $(60 \%)$ do sexo feminino. O tempo de tratamento do grupo com

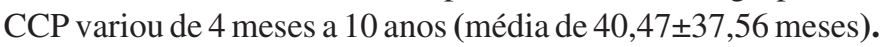

As células PMN foram encontradas em 15 (50\%) pacientes com CCP. No grupo controle, em $2(6,67 \%)$ indivíduos foram encontradas PMN, o que representa quantidade menor $(\mathrm{p}<0,01)$. Os resultados obtidos estão na tabela 1 .

No grupo com CCP, $17(56,67 \%)$ pacientes apresentaram algum grau de perda de coesão entre as células epiteliais. No grupo controle, apenas cinco $(16,67 \%)$ apresentaram comprometimento das junções intercelulares. No grupo com CCP, sete $(23,34 \%)$ pacientes apresentaram alterações mais graves das junções intercelulares e, no controle, apenas um $(3,33 \%)$. Os valores do grupo estudado são maiores do que o grupo controle $(\mathrm{p}<0,01)$ e apresentados na tabela 2 .

Impressões de mucina foram encontradas em 12 (40\%) lâminas de pacientes com CCP. Nos indivíduos do grupo controle, $25(83,33 \%)$ apresentavam mucina. A tabela 3 mostra a distribuição das impressões de mucina. O grupo controle apresentou quantidades de impressões significativamente maiores $(\mathrm{p}<0,02)$.

A tabela 4 mostra a relação núcleo/citoplasma nos pacientes estudados. No grupo com CCP, 17 (56,67\%) casos apresentavam algum tipo de alteração na relação núcleo/citoplasma e cinco $(16,67 \%)$ pacientes apresentaram alterações importantes. No grupo controle, seis $(20 \%)$ tinham algum grau de alteração dessa relação, o que foi significativamente menor do que o grupo com $\mathrm{CCP}(\mathrm{p}<0,04)$.

A distribuição das células caliciformes nos dois grupos estudados não apresentou diferença estatisticamente significante (Tabela 5).

\begin{tabular}{|c|c|c|c|c|}
\hline PMN & Grupo & com CCP & Grupo controle & Total \\
\hline Ausentes & & 15 & 28 & 43 \\
\hline Alguns & & 12 & 2 & 14 \\
\hline Muitos & & 3 & 0 & 3 \\
\hline Total & & 30 & 30 & 60 \\
\hline
\end{tabular}

\begin{tabular}{|c|c|c|c|}
\hline Coesão das CE & $\begin{array}{l}\text { Grupo } \\
\text { com CCP }\end{array}$ & $\begin{array}{c}\text { Grupo } \\
\text { controle }\end{array}$ & Total \\
\hline Células coesas & 13 & 25 & 38 \\
\hline Perda leve da coesão & 10 & 4 & 14 \\
\hline Perda moderada da coesão & 6 & 1 & 7 \\
\hline Perda importante da coesão & 1 & 0 & 1 \\
\hline Total & 30 & 30 & 60 \\
\hline
\end{tabular}

\begin{tabular}{|c|c|c|c|}
\hline Mucina & Grupo com CCP & Grupo controle & Total \\
\hline Muita & 9 & 11 & 20 \\
\hline Alguma & 3 & 14 & 17 \\
\hline Ausência & 18 & 5 & 23 \\
\hline Total & 30 & 30 & 60 \\
\hline \multicolumn{4}{|c|}{$\begin{array}{l}\text { Teste do Qui-quadrado de tendência linear para a de } 5 \%(p<0,02) \\
\text { CCP: ceratoconjuntivite primaveril }\end{array}$} \\
\hline
\end{tabular}

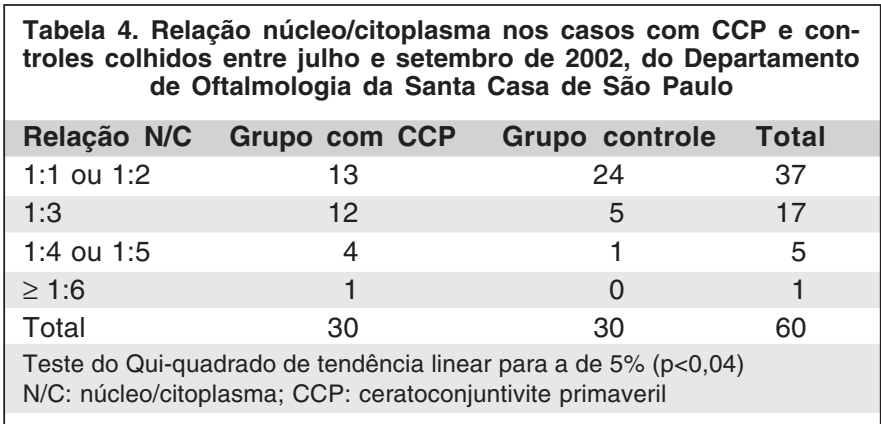

A graduação das amostras pela escala de Nelson mostrou que $12(40 \%)$ pacientes com CCP e $20(66,67 \%)$ do grupo controle apresentaram grau 0 . Os demais pacientes apresentaram algum tipo de alteração da superfície ocular e receberam outra graduação. De acordo com a escala de Nelson, os pacientes com CCP apresentaram maior envolvimento da superfície ocular $(\mathrm{p}<0,03)$. 


\section{DISCUSSÃO}

A superfície ocular dos pacientes com CCP apresentou comprometimento em todos os parâmetros avaliados através da citologia de impressão, exceto na quantidade de células caliciformes. Desta forma, a citologia de impressão mostrou que a CCP provocou alterações da superfície ocular e comprometimento do epitélio conjuntival.

Células polimorfonucleares (PMN) são encontradas nos processos inflamatórios e caracterizam resposta celular inespecífica aos antígenos que desencadeiam e perpetuam a doença. Como a CCP é uma doença inflamatória, foram encontradas PMN na conjuntiva destes pacientes em quantidade variável e significativa. Embora seja uma resposta inespecífica, representa atividade inflamatória no epitélio conjuntival ${ }^{(1,3)}$.

As junções intercelulares avaliadas por meio do grau de coesão entre as células epiteliais mostraram que as células estão menos coesas nos pacientes com CCP. A inflamação crônica sobre o epitélio conjuntival provoca a destruição das junções intercelulares e conseqüente perda da coesão entre as células epiteliais. Com isso, há desorganização da morfologia normal do epitélio e das relações intercelulares, o que, possivelmente, permite a penetração dos alérgenos e células inflamatórias nas camadas mais profundas da conjuntiva ${ }^{(3)}$.

A relação núcleo/citoplasma foi significativamente comprometida nos pacientes com CCP em intensidade variável, desde uma leve mudança na relação núcleo/citoplasma (1:3 ou $1: 4$ ) até a presença de células epiteliais grandes, com núcleos

\begin{tabular}{|l|ccc|}
\hline \multicolumn{4}{|c|}{$\begin{array}{l}\text { Tabela 5. Quantidade de células caliciformes nos casos com CCP } \\
\text { e controles colhidos entre julho e setembro de 2002, do Departa- } \\
\text { mento de Oftalmologia da Santa Casa de São Paulo }\end{array}$} \\
$\begin{array}{l}\text { Células } \\
\text { caliciformes }\end{array}$ & $\begin{array}{c}\text { Grupo } \\
\text { com CCP }\end{array}$ & $\begin{array}{c}\text { Grupo } \\
\text { controle }\end{array}$ & Total \\
Muitas & 13 & 14 & 27 \\
Algumas & 10 & 9 & 19 \\
Raras & 4 & 6 & 10 \\
Ausentes & 3 & 1 & 4 \\
Total & 30 & 30 & 60 \\
Teste do Qui-quadrado de tendência linear para a de $5 \%(p<0,67)$ & \\
CCP: ceratoconjuntivite primaveril & \\
\hline
\end{tabular}

\begin{tabular}{|c|c|c|c|}
\hline \multicolumn{4}{|c|}{$\begin{array}{l}\text { Tabela 6. Graduação de acordo com a escala de Nelson dos caso } \\
\text { com CCP e controles colhidos entre julho e setembro de 2002, d } \\
\text { Departamento de Oftalmologia da Santa Casa de São Paulo }\end{array}$} \\
\hline $\begin{array}{l}\text { Escala de } \\
\text { Nelson }\end{array}$ & $\begin{array}{l}\text { Grupo } \\
\text { com CCP }\end{array}$ & $\begin{array}{l}\text { Grupo } \\
\text { controle }\end{array}$ & Total \\
\hline Grau 0 & 12 & 20 & 32 \\
\hline Grau 1 & 15 & 9 & 24 \\
\hline Grau 2 & 2 & 1 & 3 \\
\hline Grau 3 & 1 & 0 & 1 \\
\hline Total & 30 & 30 & 60 \\
\hline \multicolumn{4}{|c|}{$\begin{array}{l}\text { Teste do Qui-quadrado de tendência linear para a de } 5 \%(p<0,03) \\
\text { CCP: ceratoconjuntivite primaveril }\end{array}$} \\
\hline
\end{tabular}

picnóticos ou ausentes e bordas dobradas. Quanto maior a alteração nessa relação e na morfologia das células epiteliais, maior o grau de metaplasia escamosa provocada pela cronicidade ou intensidade da doença ${ }^{(1)}$. Com isso, as células perdem a função de barreira contra agressões externas, já que seu funcionamento está comprometido.

A mucina, produzida pelas células caliciformes, é um dos componentes do filme lacrimal e serve de barreira contra os alérgenos que provocam e perpetuam a inflamação. A menor quantidade de mucina leva à formação de um filme lacrimal que não é capaz de proteger a superfície ocular contra os alérgenos. A lubrificação da superfície ocular também fica prejudicada e pode provocar sintomas como embaçamento visual e sensação de corpo estranho. No grupo estudado, a quantidade de mucina encontrada foi menor do que o grupo controle. Este achado difere de alguns autores ${ }^{(1)}$, que observaram aumento na quantidade de mucina e associaram isso ao aumento das células caliciformes encontrado naquele estudo.

Não houve diferença na quantidade de células caliciformes entre os grupos estudados $(p=0,67)$. Entretanto, alguns trabalhos relatam alteração no número de células caliciformes, que pode estar aumentado ${ }^{(1)}$ ou diminuído ${ }^{(12)}$. Logo, não há consenso na literatura sobre os efeitos da CCP na quantidade destas células. Estudos futuros com amostras maiores e com a contagem das células caliciformes em vários campos diferentes de cada lâmina poderão apresentar resultados diferentes.

A graduação utilizando a escala de Nelson ${ }^{(11)}$, por considerar vários dos parâmetros estudados, mostra que os pacientes com CCP têm comprometimento generalizado da superfície ocular. Entretanto, a escala de Nelson ${ }^{(7)}$ não foi adequada para avaliar a conjuntiva destes pacientes, pois, em vários casos, encontramos pouca alteração das células epiteliais, mas comprometimento importante das células caliciformes. Desta forma, a descrição de todos os parâmetros observados na citologia de impressão com a elaboração de outra escala podem ter maior utilidade na avaliação geral do impacto da doença sobre a superfície ocular.

A citologia de impressão não foi capaz de demonstrar a presença de eosinófilos na conjuntiva de pacientes com CCP, achado que confirmaria o diagnóstico da doença. $\mathrm{O}$ exame complementar mais indicado para o diagnóstico é o raspado de conjuntiva corado pelo Giemsa ${ }^{(7,13-14)}$. Entretanto, o diagnóstico da doença é clínico e o objetivo do estudo foi avaliar as alterações da conjuntiva através da citologia de impressão em pacientes com diagnóstico confirmado de CCP.

\section{CONCLUSÃO}

Neste estudo, algumas características da amostra como o número pequeno de casos, o uso pregresso de colírios e o tempo variável de tratamento podem ter influenciado nos resultados. Não há estudos que mostrem se as drogas usadas no tratamento da CCP provocam danos ao epitélio conjuntival detectáveis pela citologia de impressão. Também não há estu- 
dos comparando tempo de doença ou forma da CCP. Estes fatores podem apresentar diferentes graus de comprometimento da superfície ocular, já que olhos expostos por mais tempo à inflamação podem ter superfície mais comprometida.

A citologia de impressão conjuntival foi um exame fácil, rápido, não invasivo e indolor para avaliar a superfície ocular e foi útil para mostrar o comprometimento da conjuntiva nessa doença. Novos estudos serão importantes para determinar como a citologia de impressão poderá ser usada na condução dos casos de CCP, ajudando na avaliação da resposta terapêutica e na evolução da doença.

\section{ABSTRACT}

Purpose: To study conjunctival surface changes caused by chronic inflammation in vernal keratoconjunctivitis using impression cytology. Methods: Samples of conjunctival epithelium were collected from 30 patients with vernal keratoconjunctivitis and 30 patients without ocular diseases that were used as a control group. Each sample was collected from the superior bulbar conjunctiva using filter paper with $0.45 \mu \mathrm{m}$ pores. The material was then fixed and dyed with PAS, HE, and modified Papanicolaou. The tissue was examined with an optical microscope evaluating the following parameters: polymorphonuclear cells, intercellular junctions, mucin, goblet cells, and nuclear/cytoplasm (N/C) ratios. Thereafter, each sample was graded using the Nelson classification. Results: Samples from patients with vernal keratoconjunctivitis presented larger amounts of polymorphonuclear cells, smaller amounts of mucin, and more alterations in the nuclear/cytoplasm ratios than in the control group. The amount of goblet cells did not vary. The Nelson classification showed a general inflammatory involvement of the conjunctiva in vernal keratoconjunctivitis. Conclusion: Impression cytology was able to evaluate and characterize the degree of inflammatory involvement of the conjunctiva in vernal keratoconjunctivitis.

Keywords: Conjunctiva/cytology; Conjunctivitis, allergic; Cytological techniques

\section{REFERÊNCIAS}

1. Aragona P, Romeo GF, Puzzolo D, Micali A, Ferreri G. Impression cytology of the conjunctival epithelium in patients with vernal conjunctivitis. Eye. 1996;10(Pt 1):82-5

2. Berdy GJ, Hedqvist B. Ocular allergic disorders and dry eye disease: associations, diagnostic dilemmas and management. Acta Ophthalmol Scand. 2000;Suppl 230:32-7.

3. Jackson WB. Differentiating conjunctivitis of diverse origins. Surv Ophthalmol. 1993;38(Suppl):91-104.

4. Rivasi F, Cavallini GM, Longanesi L. Cytology of allergic conjunctivitis. Presence of airbone, nonhuman elements. Acta Cytol. 1992;36(4):492-8.

5. Belfort R, Marbeck P, Hsu CC, Freitas D. Epidemiological study of 134 subjects with allergic conjunctivitis. Acta Ophthalmol Scand. 2000;78(1):38-40.

6. Sapçi T, Gürdal C, Onmus H, Gokdermir Ö, Özkurt Y, Sengör T, Akbulut UG. Diagnostic significance of impression cytology in allergic rhinoconjunctivitis. Am J Rhinol. 1999;13(1):31-5.

7. Dewan S, Mittal S, D'Souza, Logani KB. Cytological evaluation of conjunctival scrape smears in cases of conjunctivitis. Indian J Pathol Microbiol. 1992;35(2):118-24.

8. Egbert PR, Lauder S, Maurice DM. A simple conjunctival biopsy. Am J Ophthalmol. 1977;84(6):798-801.

9. Barros JN, Mascaro VL, Gomes JAP, Freitas D, Lima ALH. Citologia de impressão da superfície ocular: técnica de exame e de coloração. Arq Bras Oftalmol. 2001;64(2):127-31.

10. Gadkari SS, Adrianwala SD, Prayag AS, Khilnani P, Mehta NJ, Shaha NA Conjunctival impression cytology - a study of normal conjunctiva. J Postgrad Med. 1992;38(1):21-3.

11. Byrne KA, Burd EM. Diagnostic microbiology and citology of the eye. London: Butterworths; 1995.

12. Toda T, Shimazaki J, Tsubota K. Dry eye with only decreased tear break-up time is sometimes associated with allergic conjunctivitis. Ophthalmology. 1995;102(2):302-9.

13. Versura P, Profazio V, Cellini M, Torreggiani A, Caramazza R. Eye discomfort and air pollution. Ophthalmologica. 1999;213(2):103-9.

14. Paschides CA, Petroutsos G, Psilas K. Correlation of conjunctival impression cytology results with lacrimal function and age. Acta Ophthalmol (Copenh). 1991;69(4):422-5. 